\title{
Stuttering Disorder Therapy Using Aristotle's Rhetoric Method In The King's Speech Movie
}

\author{
Mas Alwis Imru'ul Qais As-syauqi, alwiswae@gmail,com, UNESA, Surabaya, Indonesia \\ Slamet Setiawan, slametsetiawan@unesa.ac.id, UNESA, Surabaya, Indonesia
}

\begin{abstract}
Stuttering is a speech disorder caused by many aspects such as trauma, incident, and illness because there is no one born with this kind of speech disorder. This study focuses on how Fluency Shaping Therapy and Stuttering Modification Therapy were used by Lionel, which can reduce Bertie's stuttering utterance. In addition, this study is using the descriptive qualitative method to analyze and describe the data. Moreover, this study is in the form of dialogues between Bertie and Lionel collected from The King's Speech movie using an analysis document. Then, the collected data is analyzed by data condensation, data analysis, and conclusion. The result shows that these two stuttering treatments (stuttering modification and fluency shaping, which is part of motor learning study) can be effective therapies because they have procedures that can support each other.
\end{abstract}

In conclusion, stuttering is not an illness that humans are born with but can be caused by many things, and this speech disorder cannot be cured. However, it is reduced and modified using two methods, stuttering modification and fluency shaping therapy. Both of them can be combined with Aristotle's Rhetoric to teach public speaking, especially those who are having problems with stuttering.

Keywords: Stuttering, speech, therapy, stuttering modification, fluency shaping

\section{INTRODUCTION}

In general, people will get nervous when speaking in public or in their daily interactions with others. Some people with the trait are anxious about communicating in public and worried about their speaking skills in certain kinds of circumstances (Booth-Butterfield \& BoothButterfield, 2004). This situation has also happened to the people with a speech disorder, called stuttering, a type of speech disorder that affects the fluency of speech production in the forms of repetitions, prolongations, and blocking speech sounds production that was produced by the sufferer that impacts their communication fluency (Richard M. Arenas, 2016). In some cases, it can be caused by illness or anxiety and fear toward strangers when the person has a speech or presentation. This kind of disorder cannot be "cured," but it can be treated to reduce the stuttering to make them more fluent in communication (Ronald B. Gillam, 2011). From a psychological point of view, people who usually stutter also experience social anxiety disorder or social phobia that make them feel as minority group because of psychosocial repercussions by society such as bullying and avoiding them that increase their anxiety and fear or even decrease their confidence and trust toward society (Elaine Blumgart, 2010)

55 | IJET| Volume. 10, Issue 1. July 2021 Copyright 2021 Mas Alwis Imru'ul Qais As-syauqi and Slamet Setiawan are licensed under Creative Commons Atrribution- ShareAlike 4.0 International License. 
One example of the stuttering disorder can be found in The King's Speech movie, a story of Britain's Prince Albert, Bertie, who cannot give a speech in public because of his stuttering disorder. Bertie was not born with this kind of illness; his caretaker was caused by a kid who always treated him harshly. All of the trauma he got from his childhood affects his psychology and influences his speech fluency, making him stutter until he got older. He had come to many therapists, but no one of them could cure him. Until one day, his wife brought him to an Australian speech and language therapist named Lionel Logue, the one who can treat his stutter speech. It took several months and several kinds of treatment for Logue to make Prince Albert speak, usually toward strangers or in public. The men became friends as they work together. After his brother abdicated the throne, the new king relied on Logue to help him make his first wartime radio broadcast on Britain's declaration of war on Germany in 1939.

The recent studies also investigate stuttering disorder based on its three characteristics: repetition, prolongation, and block that occur in their subject of the study. Iriyanti investigated the stuttering phenomenon that occur in the Parental Guidance movie. She described and identified stuttering characteristics in Turner Simmon's utterances using Hedge and Davis's Theory. She used Stromsta's Theory to analyze the stuttering sounds that were produced by Simmon (Iriyanti, 2016). Another study also identified three characteristics of stuttering was conducted by Darmadie. The subject of the study is an adult male stutter speaker and his developmental stuttering. She used Syder's theory to identify those three stuttering characteristics in her subject, then calculated the frequency of the occurrence of each stuttering characteristics (Darmadie, 2012). On the other hand, some studies investigate the social impact on the stutterer's condition in terms of social anxiety (Elaine Blumgart, 2010) and Janine Diehla (2018), who examined a negative influence on social, emotional, and mental health on AWS (adult with a stutter). Likewise, Alqhazo, Blomgren, Roy, and Abu Awwad (2017) and Walden and Lesner (2018) investigate society's attitude toward people with a stutter and how lousy experience in community such social rejection, discrimination, and bullying could have a significant impact to the stutterer.

However, both Iriyanti and Darmadie are investigated stuttering from general perspectives of stuttering characteristics. Meanwhile, this research will not focus on those stuttering characteristics but more focus on how Fluency Shaping Therapy and Stuttering Modification Therapy were used by Lionel, which can reduce Bertie's stuttering utterance in King's Speech movie. Next, all the results will be connected to Aristotle's Rhetoric Theory, Ethos, Pathos, and Logos, to examine the public speaking anxiety of Bertie as the person with stutter condition then compare it with the previous study that investigates social impact toward people with a stutter.

According to Courtney T. Byrd and Ronald B. Gillam, in their book Communication sciences and disorders: from science to clinical practice, there are two kinds of stuttering disorders, which are Primary and Secondary Stuttering Behaviors. When it comes to "core behaviors" speech disfluencies were mentioned earlier (repetitions, prolongations, and blocking) are called Primary Stuttering Behaviors. People who stutter often produce three or four rapid repetitions of sounds such as repetition single-syllable words (My, my, my car was stolen), syllable repetitions (My ca-ca-car was stolen), or sound repetitions (M, m, my vehicle was stolen). They may also prolong some sounds a little longer than usual (My car was stolen),

56 | IJET| Volume. 10, Issue 1. July 2021 Copyright 2021 Mas Alwis Imru'ul Qais As-syauqi and Slamet Setiawan are licensed under Creative Commons Atrribution- ShareAlike 4.0 International License. 
and this prolongation may be audible or inaudible. An inaudible sound prolongation where the mouth can produce the sound for several seconds, but no sound is coming out, called a block. These speech disfluencies made by people who stutter disturb their communication ability effectively and may cause a negative impact on the speakers' emotional reaction toward their speech. Meanwhile, counterproductive adaptations or an action by the people who stutter to avoid them to produce speech disfluencies such blink their eyes, purse their lips, open their jaws, stamp the floor with their feet, or even insert $u$ h right before a word that they anticipate is stuttering, called as Secondary Stuttering Behaviors.

There are two types of treatment for stuttering. First is Stuttering Modification Therapy, used to help the people who stutter to change or modify their stuttering instead to cure it. It was introduced by Charles Van Ripper, his approach known as MIDVAS, which stands for motivation, identification, Desensitization, variation, approximation, and stabilization. The attitudes and feelings about stuttering play a critical role in the development of the disorder, and the four of the six stages of the MIDVAS approach (motivation, identification, Desensitization, and stabilization) relate to the ability of the people who stutter to deal with their stuttering (Ronald B. Gillam, 2011). The second is Fluency Shaping Therapy, a new speech style called motor learning and control, used to reduce stuttering or teach the stutterer how to talk fluently, such as slower speech rates, relaxed breathing, phonation, and articulation which is part of three motor learning stages. The main difference between these two approaches is the focus on stuttering attitudes and emotions. Stuttering change modification focuses on this, but fluency shaping therapy does not (Kehoe, 2006).

57 | IJET| Volume. 10, Issue 1. July 2021 Copyright 2021 Mas Alwis Imru'ul Qais As-syauqi and Slamet Setiawan are licensed under Creative Commons Atrribution- ShareAlike 4.0 International License. 
Note: Adapted from Communication sciences and disorders: from science to clinical practice (p 175), by Ronald B. Gillam, Thomas Marquardt, and Frederick Martin, 2011, Sudbury: Massachusetts, Jones and Bartlett Publishers, LLC.

Another theory used in this research is Rhetoric Theory, proposed by the Greek philosopher Aristotle. According to Hendrikus in his book entitled Retorika, Terampil berpidato, berdiskusi, berargumentasi, bernegosiasi, three main concepts in his theory are: Ethos, Pathos, and Logos. The first is Ethos or credibility, which means how the speaker convinces the listeners through the idea he presented. Also, credibility is another point that the speaker has to consider in his speech. The second is Pathos, or emotional, which means the speaker's ability to draw the listeners' attention. However, aspects such as language choice and the speaker's body posture in front of his audience are essential to attract the listeners' attention and emotion. The third one is Logos or Logical, which means the speakers have to use a proper technique in delivering their speech, reflecting the speaker's knowledge. In public speaking, the speaker needs to consider their three abilities if he wants to deliver a good speech (Hendrikus, 1991).

\section{METHOD}

The data will mainly be taken from The King's Speech movie. The subject of this study is Bertie or King George VI, who is a main character in The King's Speech movie that represents the actual stutter condition. This research takes the data in dialogues between Logue and Bertie directly from the cinema concerning Bertie's stuttering disorder. Later, the data will

58 | IJET | Volume. 10, Issue 1. July 2021 Copyright 2021 Mas Alwis Imru'ul Qais As-syauqi and Slamet Setiawan are licensed under Creative Commons Atrribution- ShareAlike 4.0 International License. 
be used in the analysis using a descriptive qualitative approach. The Data is also taken from international journals as previous studies to support the purpose of this study.

The collected data based on the problem will be analyzed, and to make the analysis reliable, both combination approaches, Stuttering Modification Therapy (as supporting theory) and Fluency Shaping Therapy (as the lealeading theory), are applied to support the argumentation and interpretation in the analysis process toward Logue's therapy on Bertie's stuttering disorder. This research will focus on how Lionel Logue treats Bertie's stuttering disorder related to those approaches and how it can be used in English learning and teaching process toward the student who is experiencing stuttering in public speaking or the learning process. The researcher takes the lealeading role; in fact, the researcher is the one who collects all of the information needed in this study.

\section{RESULT AND DISCUSSION Discussion ( $\left.1^{\text {st }}\right)$}

Data 1

Bertie: Aren't you going to start treating me, Dr. Logue?

Lionel: Only if you're interested in being treated.

Based on Data 1, the motivation stage from Stuttering modification therapy is used early in the movie when Bertie's first encounter with Lionel. This stage focuses on preparing the client mentally and emotionally for the therapy steps that will undergo by the clients. In this part, Lionel is trying to pursue Bertie's self-motivation is being treated because of how therapy could go well if the patient does not dare to get cured. By convincing him about his field of expertise and explaining if no infant starts to speak with a stammer, it must be something behind it that caused this kind of language disorder. At the same time, by getting the client's trust, Bertie, Lionel can reduce his fear about his stammer. This is also part of Stuttering modification therapy which is the Desensitization stage. This stage is focused on reducing the client's fears, frustrations, and embarrassment about his stammer.

Data 2

Lionel: So... when you talk to yourself, do you stammer?

Bertie: No... of course not.

Lionel: Well, that proves that your impediment isn't a permanent part of you.

The identification stage is applied here by Lionel, slowly provoke Bertie to talk about his earliest memory about the cause of his language disorder, stammer, which is not a permanent part of him. In this stage, the focus is to help the client understand and explain his stuttering. However, first, the procedure also must be followed: the client must describe his own stuttering in detail, what kind of situation he fears the most, what kind of words he is usually hard to speak, and any others. Discussing the client's feelings about his stammer is also essential because it is also part of the therapy procedure, the motivation stage. Bertie refuses to answer questions concerning his stuttering that is related to his past. It is not because of his fear toward Lionel, the person he just met, but because of his frustration toward his illness and his belief if no one can fix it.

59 | IJET| Volume. 10, Issue 1. July 2021 Copyright 2021 Mas Alwis Imru'ul Qais As-syauqi and Slamet Setiawan are licensed under Creative Commons Atrribution- ShareAlike 4.0 International License. 
Data 3

Bertie: I... I stammer.

No one can fix it.

Lionel: I'll bet you that you can read flawlessly, right here, right now.

And if I win the bet, I get to ask you more questions.

Bertie is persistent if his stammer cannot be cured and no one can threaten it, which depicts his frustration toward his stuttering. Replying to his patient's condition, Lionel tries to show that his illness can be cured, even though he has to use a little bit of persuasion (betting challenge) to Bertie. It is also part of Desensitization in the Stuttering modification therapy. When the client can overcome his fears, frustrations, and embarrassment about his stammer, it helps the process of treatment by building motivation inside the client's self. Knowing more information by giving several questions regarding his stammer is part of the identification stage. If the client cannot provide the detail of his stuttering, it will inhibit the therapy process. However, it also depends on each therapist what kind of strategy they use to get more information regarding their patient stammer condition based on the procedure of this therapy method. There is a possibility that negative emotional reactions to stuttered disfluencies may produce a more negative outcomes for the stutterer (Walden \& Lesner, 2018).

Data 4

Bertie: You're playing music!

Lionel: I know.

Bertie: So how can I hear what I'm saying?

Lionel: Well, surely a prince's brain knows what its mouth's doing?

Lionel asks Bertie to read a book in the usual way, but it did not go well. The second time, he urges Bertie to do the same thing, read a book, but in specific condition, he records Bertie's voice using a recording machine and then plays it back to him; Bertie must wear an earphone while at the same time the device records his voice. This part of the movie shows the stammer become stutter because they are always concerned about what they are saying; in this condition, they just increase the fear and frustration toward the words that they will produce or pronounce. The identification stage is applied here, which is identified as the cause that makes Bertie suffer. He could not speak fluently because he was interrupted by prolongation, repetition, or blockages caused by his fear of speaking.

Data 5

Lionel: We need to relax your jaw muscles, strengthen your tongue by repeating tongue twisters.

For example, "I'm a thistle-sifter. I have a sieve of sifted thistles and a sieve of unsifted thistles. Because I am a thistle-sifter".

Bertie: Fine.

Lionel: And you do have a flabby tummy, so we'll need to spend some time strengthening your diaphragm.

60 | IJET| Volume. 10, Issue 1. July 2021 
According to data 4, the scene when Bertie leaves Lionel's consultation room, guessing that Lionel was playing with him. Several days after the moment, he played the phonograph that Lionel gave, unexpectedly the voice who speak fluently without a single stutter word from the recorder is him. He decided to come back to Lionel's place to get himself treated. Data 5 above is part of the motivation stage in Stuttering Modification Therapy, the third procedure 'explaining the course of therapy.' It is also part of Fluency-Shaping Therapy, simply called motor learning, cognitive, associative, and autonomous stage. When it comes to stuttering using this technique, the stutter needs to practice every day because this technique will help loosen the jaw muscles and tongue and strengthen the diaphragm, such as the tongue twisters mentioned in Data 5 above.

Data 6

Lionel: Feel the looseness of the jaw.

Good. Little bounces. Bounces.

Shoulders lose, shoulders lose.

Beautiful, beautiful, beautiful.

Now, loose.

The articulation stage is used in this scene based on Data 6 when Lionel asks Bertie to hum by opening his jaw as the focus on loosening his jaw muscles. It will help to relax the production of speech muscles for all sounds. Tensing lips, tongue, and jaw too much and holding the tension too long; is a common mistake using this technique. While loosening the shoulder is helped Bertie to reduce his tense while producing speech sounds.

Data 7

Lionel: Take a nice deep breath.

Expand the chest.

Put your hands onto your ribs.

Deeper. Good.

How do you feel?

Bertie: Full of hot air.

Lionel: Isn't that what public speakings is all about?

Take a good deep breath, and up comes Your Royal Highness. And slowly exhale, and down comes Your Royal Highness.

According to Data 7, it is the Relaxed Breathing stage of Fluency-Shaping Techniques, controlling airflow in and out by putting hands in the stomach or the ribs and taking a small breaths (the time while inhaling and exhale have to be equal), which is called diaphragmatic breathing. The other breathing technique is upper-chest breathing or thoracic breathing, taking a deep breath using the upper chest muscles to expand the lugs while maintaining the upper chest muscles tension (in the movie, Bertie's wife sit on his chest while he sleeps on the floor) to keep the air in the lungs as long as possible, then exhale slowly as possible, next after all the air inside was gone, quickly take another breath (to fill the lung as fast as possible). Practicing to switch between thoracic and diaphragmatic breathing is a technique to increase lung

61 | IJET| Volume. 10, Issue 1. July 2021 Copyright 2021 Mas Alwis Imru'ul Qais As-syauqi and Slamet Setiawan are licensed under Creative Commons Atrribution- ShareAlike 4.0 International License. 
capacity. This stage is quite simple, but it has to be repeated and practiced repeatedly until the body is used to it that will help stuttering therapy processes.

Data 8

Bertie: Mmm... Mother.

Lionel: Shorten the humming each time.

Bertie: Mother. Mmm...

Lionel applies slow Speech with Stretched Vowels in this scene, instead of stretching the vowel, this moment of the movie shows Lionel focused on trying voice consonants rather than vowel such $/ \mathrm{m} /, / \mathrm{n} /, / \mathrm{r} /$ a little bit longer than usual speech, but in this case, it is not longer than vowels. Ordinary people usually take one second per syllable in speaking, while stutterers take more than around two to three syllables per second. Lionel though Bertie to stretch $/ \mathrm{m} /$ sound in the word "mother" longer than moving to the next voice sound, which is to reduce the time of the $/ \mathrm{m} /$ sound bit by bit to make his tongue and jaw muscles get used to it (until he could pronounce that word like ordinary people).

Data 9

Bertie: A cow, a cow...

Lionel: A king.

Bertie: A... a king...

This stage is called cancellation, the first procedure in the Stuttering Modification Therapy approximation phase (Table 7.10). Lionel taught Bertie how to stop as soon as he stutters a word is spoken or pause when he encounters the consonants that he struggles to pronounce fluently, and then easily repeat the word (to be sounded as fluent as possible). It is a simple method for ordinary people, but it will be difficult for stutterers like Bertie to pause while producing speech. That is why the stutterer has to adapt themself in their stutter condition to hide their stutter become a 'pause' in the way they speak by using this cancellation method (the researcher concluded it as stutter in style).

Data 10

Lionel: Anyone who can shout vowels at an open window can learn to deliver a speech.

In this data 10, Lionel also uses Slow Speech with Stretched Vowels but no focused-on consonant such in Data 9, but instead in vowel sound /a/ and /i/ sound (in minutes 1.38.23, in the movie). While shouting vowels at open window around fifteen seconds as Bertie did in the film, maybe for ordinary people it is a little bit silly, but, on the other side, this method is used to see how long the stutterer can produce sounds after practicing the two techniques, thoracic and diaphragmatic breathing in the previous therapy procedure (to measure if the jaw muscles, tongue, and diaphragm have adapted as its usual condition).

Data 11

Lionel: Good. Deep breath, and...

Let the words flow.

62 | IJET| Volume. 10, Issue 1. July 2021

Copyright 2021 Mas Alwis Imru'ul Qais As-syauqi and Slamet Setiawan are licensed under Creative Commons Atrribution- ShareAlike 4.0 International License. 
Bertie: No, it doesn't bloody work.

Lionel: Come on, one more time, Bertie. You can do it.

Bertie: A sieve of thisted syphilis.

It is already mentioned in Data 5, and in the movie, Lionel explained if repeating tongue twisters is to relaxing jaw muscles and strengthening the tongue. This stage is called the autonomous stage in the motor learning process, which is practiced by the muscle's movements faster and harder. In this stage, it is already beyond the first two motor learning stages, cognitive and associative scenes, or the next step/level of Fluency Shaping Techniques. The stutterer must practice speaking as fluently as possible and faster practicing tongue twister words. In a simply way, shorten syllable duration from three seconds, to two seconds, to one second until the speed limit of the stutterer. However, this method must be practiced repeatedly with relaxed, quiet speech and with loud, forceful speech until the speech production's muscles become normal.

Data 12

Lionel: Father.

Bertie: Father.

Lionel: Father.

Aim for the at-h.

Bertie: Father.

The Data 12 above shows pull-outs, the second procedure in the approximation phase in Stuttering Modification Therapy. This method is to increase airflow to help the stutterer struggling, especially during a block sound such as Bertie in the movie who struggled with /f/ sound in 'father' word. Commonly, every stutterer has their difficulties producing some consonants or vowels, even in the form of repetitions, prolongations, and blocking; the therapist must use what kind of approximation phase procedures suit the patient. Cancelation procedure is more suitable for those who are struggle with repetitions and prolongations. Pull-outs are more suitable for blocking, and the last preparatory set for those who already have the ability to use Cancelation and Pull-outs or can be introduced it before those two approximation phase procedures.

Data 13

Bertie: $\delta$ You're barking up the wrong tree now, Doctor, Doctor $\delta$

Lionel: $\delta$ Lionel $\delta$

See? You didn't stammer.

Bertie: Of course I didn't stammer; I was singing.

The moment after King George V's death, Bertie ccomes to Lionel's place to get someone to talk to, especially while in a dark moment like this. This scene shows that Lionel already gets Bertie's trust towad him because this relation between therapist and patien significant for the success of the therapy procedures. He told Lionel about his therapy progress while at home, practicing an hour a day that was already mentioned in Data 5 above; a therapy process needs intense practice for the patient. According to the Data 13, while Bertie tries to speak but his stammer holds him to do so, Lionel told him to sing it (words that he wants to

63 | IJET| Volume. 10, Issue 1. July 2021 Copyright 2021 Mas Alwis Imru'ul Qais As-syauqi and Slamet Setiawan are licensed under Creative Commons Atrribution- ShareAlike 4.0 International License. 
say), which is helped him to get the flow while saying continuous sounds. It is the part of Stuttering Modification phase, approximation, the third procedure, Preparatory sets using tone or singing when he encounters stammer. Lionel introduced this procedure to Bertie after knowing how to use Cancellations and Pull-outs to modify his stuttering.

Data 14

Lionel: Are you naturally right-handed?

Bertie: Left.

I was... punished, and now I use the right.

Lionel: Yes, that's very common with stammerers.

In the scene when Bertie puts some glue on the struts of the plane miniature, Lionel realizes that Bertie is naturally right-handed, which is very common with stammerers. In a study related to this matter, Kushner stated that many psychologists, psychiatrists, and educators from British and American proposed forcing left-handed children to write with their right hands that last for several decades in the stuttering field of study. However, forcing natural left-handed person especially kids, to write and do other tasks with their right hand may cause negative consequences, especially stuttering that shows if stammers displayed weak laterality (Kushner, 2012).

\section{Data 15}

\section{Lionel: Who were you closest to in your family?}

Bertie: Nannies.

Not my first nanny. She...She loved David. Hated me.

When we were......presented to my parents for the daily viewing, she would... she'd pinch me so that I'd cry and be handed back to her immediately.

And then she would...

Lionel: Sing it.

Bertie: $\delta$ Then she wouldn't feed me

Based on the previous explanations above, in Data 2, in the identification phase, Bertie refused to explain the case of his stuttering in detail. Still, in this scene, he finally dares to tell Lionel about his past life when he was a boy. Data 15 shows that Bertie's stuttering was caused by the harsh treatment of his first nanny, who loved his brother David more than him, and this happened for over three years. This explanation is related to Data 2 when Lionel told Bertie if stutter isn't a permanent part of him, caused by external causes such as trauma, accident, etc. Lionel applied two phases of Stuttering Modification Therapy: identification (getting in-depth client information about his stuttering) and approximation (modified his stuttering using song, which was explained in Data 14) phases.

Data 16

Bertie: You know......Lionel, you're......you're the first ordinary Englishman...

Lionel: Australian.

Bertie: ...I've ever really spoken to.

64 | IJET $\mid$ Volume. 10, Issue 1. July 2021 
This Data above can measure the outcome of Lionel's therapy procedure using both methods, Stuttering Modification and Fluency Shaping therapy. It shows that a stammer like Bertie could speak to other strangers by putting aside his fear of his stammer. On the other hand, the relationship between the therapist and the client is an integral part of the therapy process because the stammer must overcome social anxiety disorder or social phobia. A study related to social anxiety shows that adults who stutter commonly experience difficulty having a speech in public caused by the self-perceived and physiological stress related to various speaking conditions (Janine Diehla, 2018).

Data 17

Bertie: My brother.

I couldn't say a single word to him in reply.

Lionel: Why do you stammer so much more with David than you ever do with me?

Bertie: Because you're bloody well paid to listen.

Lionel: Bertie, I'm not a geisha girl.

Stuttering Modification therapy's success can be seen in Data 17, especially motivation, identification, and desensitization phases such as Bertie's awareness of his fear, bit by bit already gone even when having a conversation with Lionel. Still, he does stammer so much while talking to David. In this case, Bertie encounters this problem because he never has confidence toward himself if he is not better than his bother and looked up to him. Lionel tries to get Bertie to realize he needs not be governed by fear while speaking in any conditions or with other people. Trait anxiety is a multidimensional emotion when an individual responds to variables in the environment (Bricker-Katz, Lincoln, \& McCabe, 2009). Giving motivation or support to those who stutter is another aspect that has to be considered by the therapist for the success of the therapy process based on the Stuttering Modification approach.

Data 18

Bertie: What is it about you that bloody well makes you want to go on about him the whole bloody time?

Lionel: Vulgar but fluent.

You don't stammer when you swear.

Bertie: Bugger off!

This scene is when Bertie failed to persuade David to marry Mrs. Simpson because certain law forbids the king, as the head of the church, to marry a divorced woman. According to Data 18, Bertie does not stammer when swearing that makes him forget all about the fear, embarrassment toward his stutter when he is angry because of the complicated situation caused by his brother. Hesitation while producing speech sounds can trigger stuttering. It means that the emotions of the person who stutter in certain conditions are related to their stuttering condition, which is the proof of explanation in the previous data discussions above. However, in this case, it may be considered Practicing Under Stress, part of autonomous stage, in motor learning stages, a stuttering practice in stressful conditions.

Data 19

65 | IJET| Volume. 10, Issue 1. July 2021 Copyright 2021 Mas Alwis Imru'ul Qais As-syauqi and Slamet Setiawan are licensed under Creative Commons Atrribution- ShareAlike 4.0 International License. 
Lionel: You don't need to be afraid of the things you were afraid of when you were five.

You're very much your own man, Bertie.

Bertie: Am I?

Lionel: Your face is next, mate.

In the main event in the story, when David prefer his woman, Mrs. Wallis Simpson of Baltimore, rather than to serve his nation as the next king of Britain after the death of his father, King George V, then Bertie must ascend the throne to fulfill the duty as the second son of the royal family. Bertie comes to Lionel's place to ask for a favor, to help him with his first speech in a radio broadcast during World War II. The motivation phase is applied here; the therapist always encourages the patient to fight their fear toward their speech. Based on Data 19, because knowing that every stammer is always afraid to go back to square one, Lionel tries to strengthen Bertie's mental health regarding his psychological fear in public speaking that triggers his stutter.

Data 20

Lionel: My job was to give them faith in their voice and let them know

that a friend was listening.

That must ring a few bells with you, Bertie.

When the Star Chamber inquisition told Bertie about the background of Lionel Logue and doubting his trust toward Lionel, the truth is he is not a doctor, has no diploma, no certificate regarding speech therapy. Still, he gained his experiences about defects through war-threatening soldiers who came from front line and were unable to speak. All he did were muscle therapy, exercise, relaxation (part of fluency shaping therapy procedures) but giving the patient faith in their voice is important and tell them if there is someone who is listening to their speech to reduce their discrimination feeling such as the explanations in Data 2, 10 and 19. High percentages of negative internalized feelings were known in the form of emotions such as annoyance, embarrassment, shame, and disappointment (Alqhazo et al., 2017).

Data 21

Lionel: I'm going to see what this sounds like in the cheap seats, so even your old nanny can hear.

‘blab la blab la-

Bertie: "1 solemnly promise to do so."

Lionel: Louder.

Based on Data 21 above, it is included as an autonomous stage, Increasing Force procedure, in speech motor learning (the umbrella of Fluency Shaping therapy). Practicing speech in high volume is the focus here, but the patient has to shout or yell instead of the voice. However, vocal volume is the main issue of each exhalation volume and vocal fold tension. The high volume with normal intonations results from this technique, something that stage actors always do to make their voice heard in the back-seat row. Shortly, the stammer (such as Bertie) has to get used to a situation when he has to increase his voice volume in a large room such opera stage or the royal church, Westminster Abbey in the movie.

66 | IJET| Volume. 10, Issue 1. July 2021 Copyright 2021 Mas Alwis Imru'ul Qais As-syauqi and Slamet Setiawan are licensed under Creative Commons Atrribution- ShareAlike 4.0 International License. 
Lionel: You still stammered on the "w"

Bertie: Well, I had to throw in a few, so they knew it was me.

In the last scene, when Bertie delivered his first radio broadcast in World War 2, Lionel guided him until the end. After several treatments and practices, Bertie successfully reduced his stammer and delivered a fluent speech (especially for stutter people) through radio using techniques thought by Lionel, such as cancellations, pull-outs, and initial sets. The result of his efforts is paid off when knowing himself without any errors or stutter words for the first time in his entire life. Even Bertie still stammered on the word 'we but this is a significant achievement from the person who has this kind of speech disorder, start from zero to hero. $\mathrm{He}$ became a symbol of national resistance during the dark days of World War II at that time.

\section{Discussion $\left(2^{\mathrm{ND}}\right)$}

In this section of the study, this paper will discuss how both stuttering therapy methods can be applied to teach public speaking for the students, both for the normal ones or even the stutterer ones. Based on the first discussion, Ethos can be seen in several procedures in each therapy process such Approximation phase (cancellations, pull-outs, and initial sets) in Stuttering modification, and this procedure helps to modify the way how stutterers speak, which makes the listener could hear the words better because of clear pronunciation. The other one is the identification phase, which helps the speakers identify the listener's reaction toward their speech and convince the listener. This phase could improve stutterers speaking ability to deliver a good lesson with a clear explanation even with their stuttering. Some people (the listeners) will get confused toward the main idea or point from the speakers because of the speakers' stammer in their speech that makes the concepts they are going to deliver become unclear, besides their unclear pronunciation and bad intonation (stutterer also has difficulty with intonation in their address). The fluency shaping therapy, such as relaxed breathing, phonation, and articulation, could be remedial their speech pronunciation and intonation in public speaking, such as what Bertie has accomplished in the last scene of the movie, and it is not limited to the stutterer but also ordinary people who want to improve their speaking ability.

In the first discussion, Pathos can be seen when Lionel uses the motivation and desensitization phase to Bertie. These two phases have a different focus but support each other because these two stuttering modification procedures help the speaker (especially the stutterer) overcome their fear, frustration, and embarrassment toward their speech. However, those emotions affect body posture and word choices that speakers will use. In public speaking, the listeners would not pay attention if the speakers do not have reasonable confidence. At the same time, it can be seen through how the speakers act in front of the audience. The last is Logos, this concept can be seen in data 2, 14, and 20, when Lionel persuades Bertie with some facts regarding his stuttering, such proofing that his stuttering is not something human were born with, and he convinces Bertie that even every person has a voice to be heard which is also part of motivation and identification. Those two procedures help the stutter overcome negative emotion and confidence, which is to reduce public speaking anxiety and deal with fluency, intonation, and breathing that have to be considered while having a speech.

67 | IJET| Volume. 10, Issue 1. July 2021 Copyright 2021 Mas Alwis Imru'ul Qais As-syauqi and Slamet Setiawan are licensed under Creative Commons Atrribution- ShareAlike 4.0 International License. 
However, some studies show that people with stutter tend to have social anxiety, depression, and social phobia, which is caused by self-perceived and physiological stress related to their speaking conditions (Elaine Blumgart, 2010; Janine Diehla, 2018). In line with the discussion of Ethos above, failing to deliver the idea to the listeners in terms of unclear pronunciation and bad intonation in conversation or public speaking may reduce the speaker's self-confidence that will lead to general trauma. Moreover, the negative emotional feelings such as annoyance, embarrassment, shame, and disappointment will also produce a more excellent negative outcome for the stutterer (Alqhazo et al., 2017; Walden \& Lesner, 2018). Pathos and Logos can be a suitable treatment for stutterers and language learners who want to improve their speaking ability through overcoming their fear, frustration, embarrassment, and negative emotions to gain self-motivation to speak the language freely without worrying about making mistakes such as wrong pronunciation, intonation, and wrong word choices. The critical factor of speaking, based on three main concepts (Ethos, Pathos, Logos) of Rhetoric theory, is a willingness to communicate followed by motivation because it does not even matter how decent the material, procedures, guidance books, or approaches used by the teacher if the speakers themselves do not even have a will to use the language orally, then there would not be any motivation to improve their speaking ability (for non-stutterer) or threatening their stutter (for stutterer).

\section{CONCLUSION}

According to the data analysis above, several points can be concluded based on the first research question. First, both Stuttering therapies, Stuttering Modification and Fluency Shaping, are approaches that complete each other. At the same time, the first one is more focused on modifying the stuttering to look more fluent such as cancellation, pull-outs, and initial sets. In contrast, the second approach focuses on muscles therapy, exercise, relaxation, and speech sound practices and how the patient can get rid of his stuttering. even in the end, it is impossible this illness can be cured. Second, the psychological aspect significantly impacts the person who stutter from their surroundings (family, friend and society) that might produce negative emotions such as embarrassment, fear, discrimination, etc. Third, motivation is needed to succeed in stuttering therapy procedures, especially from the therapist and family. These two stuttering treatments (stuttering modification and fluency shaping) can be an effective treatment, ideally with an intensive schedule and group sessions (Euler, Lange, Schroeder, \& Neumann, 2014). Both therapy methods could reduce the speaker's anxiety (stutterer) and make them speak more fluent and blatant without any fear of their speech, which is the requirement to have good public speaking, based on Aristotle's Rhetoric, Eth Pathos, and Logos.

68 | IJET| Volume. 10, Issue 1. July 2021 


\section{REFERENCES}

Alqhazo, Mazin, Michael Blomgren, Nelson Roy, and Maha Abu Awwad. 2017.

"Discrimination and Internalised Feelings Experienced by People Who Stutter in Jordan." International Journal of Speech-Language Pathology 19, no. 5: 519-28.

Arenas, Richard M, and Patricia M Zebrowski. 2017. "The Relationship between Stuttering Anticipation and Verbal Response Time in Adults Who Stutter." Speech, Language and Hearing 20, no. 1: 1-14.

Blumgart, Elaine, Yvonne Tran, and Ashley Craig. 2010. "Social Anxiety Disorder in Adults Who Stutter." Depression and Anxiety 27, no. 7: 687-92.

Booth-Butterfield, M, and S Booth-Butterfield. 2004. "Communication Apprehension and Avoidance in the Classroom: A Text and Course Outline." Littleton, MA: Tapestry.

Bricker-Katz, Geraldine, Michelle Lincoln, and Patricia McCabe. 2009. "A Life-Time of Stuttering: How Emotional Reactions to Stuttering Impact Activities and Participation in Older People." Disability and Rehabilitation 31, no. 21: 1742-52.

Darmadie, Rhima Puspita. 2012. "The Characteristics of Stuttering in the Utterances of an Indonesian Male Adult with Developmental Stuttering."

Diehl, Janine, Michael P Robb, John G Lewis, and Tika Ormond. 2019. "Situational Speaking Anxiety in Adults Who Stutter." Speech, Language and Hearing 22, no. 2: 100-110.

Euler, Harald A, Benjamin P Lange, Sascha Schroeder, and Katrin Neumann. 2014. "The Effectiveness of Stuttering Treatments in Germany." Journal of Fluency Disorders 39: 111.

Gillam, Ronald B, and Thomas P Marquardt. 2019. Communication Sciences and Disorders: From Science to Clinical Practice. Jones \& Bartlett Learning.

Hendrikus, P Dori Wuwur. 1991. Retorika, Terampil Berpidato, Berdiskusi, Berargumentasi, Bernegosiasi. Kanisius.

Iriyanti, Leliana Desita. 2016. "Parental Guidance Movie: Psycholinguistics Perspective of Utterances in Turner Simmons's Stuttering." Language Horizon 4, no. 4.

Kehoe, Thomas David. 2006. No Miracle Cures: A Multifactorial Guide to Stuttering Therapy. Casa Futura Technologies.

Kushner, Howard I. 2012. "Retraining Left-Handers and the Aetiology of Stuttering: The Rise and Fall of an Intriguing Theory." Laterality: Asymmetries of Body, Brain and Cognition 17, no. 6: 673-93.

Walden, Tedra A, and Taylor A Lesner. 2018. "Examining Implicit and Explicit Attitudes toward Stuttering." Journal of Fluency Disorders 57: 22-36.

69 | IJET| Volume. 10, Issue 1. July 2021 